\title{
Basal Cell Carcinoma Overlying a Dermatofibroma: A Rare Collision Tumor
}

\author{
Sandra Jerkovic Gulin, ${ }^{1}$ Davorin Loncaric, ${ }^{2}$ Jaka Rados ${ }^{2}$
}

1 Department of Infectious Diseases, Dermatology, and Venereology, General Hospital Sibenik, Croatia

2 Department of Dermatology and Venereology, University Hospital Centre Zagreb, Croatia

Key words: basal cell carcinoma, dermatofibroma, dermoscopy, collision tumors, histopathology

Citation: Jerkovic Gulin S, Loncaric D, Rados J. Basal cell carcinoma overlying a dermatofibroma: a rare collision tumor. Dermatol Pract Concept. 2020;10(1):e2020015. DOI: https://doi.org/10.5826/dpc.1001a15

Accepted: October 1, 2019; Published: December 31, 2019

Copyright: @2019 Jerkovic Gulin et al. This is an open-access article distributed under the terms of the Creative Commons Attribution License, which permits unrestricted use, distribution, and reproduction in any medium, provided the original author and source are credited.

Funding: None.

Competing interests: The authors have no conflicts of interest to disclose.

Authorship: All authors have contributed significantly to this publication.

Corresponding author: Sandra Jerkovic Gulin, MD, Department of Infectious Diseases, Sibenik General Hospital, Stjepana Radića 83, 22221 Sibenik, Croatia. Email: sandrajerkovicgulin@gmail.com

\section{Introduction}

Dermatofibroma (DF) is one of the most frequent skin tumors. Several histopathological variants have been described, including fibrous histiocytoma (accounting for $80 \%$ of cases), aneurysmal, hemosiderotic, epithelioid, cellular, lipidized, atrophic, and clear cell variant. DF has slight female predominance and is mostly localized on the limbs. Eruptive DFs have been described in association with pregnancy and immunosuppression. In almost $80 \%$ of cases, the epidermis overlying DF shows changes that range from simple hyperplasia to the proliferation of basaloid cells, morphologically indistinguishable from basal cell carcinoma (BCC) [1]. We report a case of collision tumor consisting of $\mathrm{DF}$ and BCC.

\section{Case Presentation}

A 56-year-old woman presented with a papulonodular, erythematous, partially pigmented lesion, $18 \times 8 \mathrm{~mm}$ in size, on her right thigh (Figure 1A). The lesion was firm on palpation, revealing a pinch (dimple) sign. Dermoscopy revealed 2 parts of the tumor, a pale pink amorphous area with white areas and blue-gray ovoid nests, specks of pigment, and spokewheel pigmentation (Figure 1B). The tumor was surgically removed. Histopathology confirmed 2 different parts of the lesion (Figure 1, C and D), 1 encapsulated in the dermis consisting of mixture of fibroblasts and histiocytes arranged between collagen fibers (DF) and the other, under the overlying acantholytic epidermis, a dermal tumor consisting of islets of atypical basaloid cells forming a palisading pattern at the periphery (BCC).

\section{Conclusions}

Only several cases of BCC overlying DF have been reported in the literature [2]. We may assume, as have other authors, that basaloid proliferations (basal cell-like changes) and BCCs (true neoplastic lesions) are a result of the inductive 

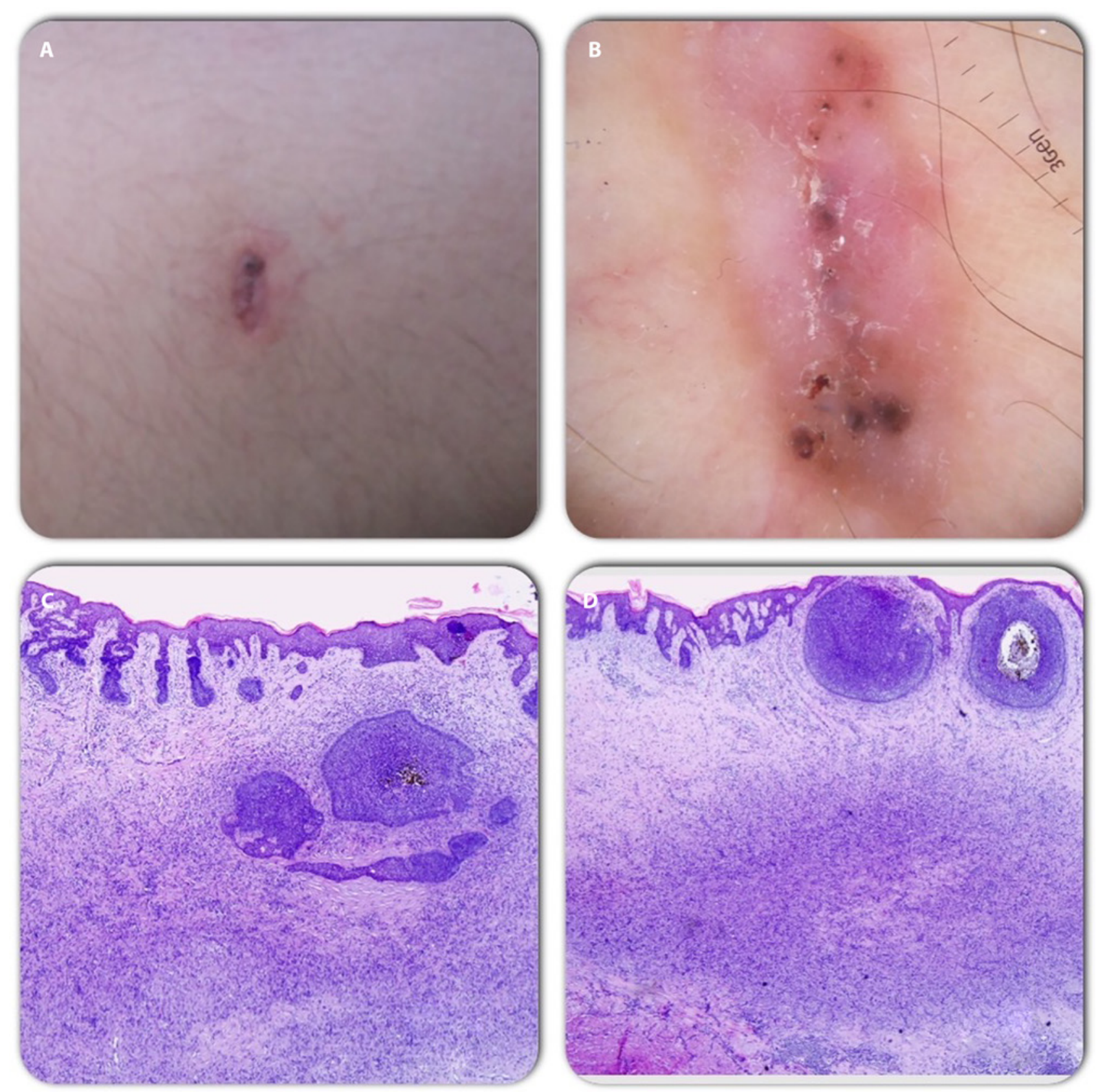

Figure 1. (A) Clinical view: papulonodular, erythematous, partially pigmented lesion, $18 \times 8 \mathrm{~mm}$ on the right thigh. (B) Dermoscopic view: 2 parts of the tumor, a pale pink amorphous area with white areas and blue-gray ovoid nests, specks of pigment, and spoke-wheel pigmentation. (C,D) Histopathology: 1 part of the lesion is encapsulated in the dermis consisting of a mixture of fibroblasts and histiocytes arranged between collagen fibers (dermatofibroma) and the other, under the overlying acantholytic epidermis, a dermal tumor consisting of islets of atypical basaloid cells in a palisading pattern at the periphery (basal cell carcinoma) (H\&E, $\times 20)$.

effect of DF and its fibrohistiocytic proliferation on the epithelial cells of the hair follicle [2]. This letter highlights the importance of dermoscopy and dermoscopic criteria in collision lesions in order not to miss skin cancer and gives a dermoscopic/histopathological description of a BCC and DF in a collision lesion.

\section{References}

1. Zaccaria E, Rebora A, Rongioletti F. Multiple eruptive dermatofibromas and immunosuppression: report of two cases and review of the literature. Int J Dermatol. 2008;47(7):723-727.

2. Córdoba S, Hernández A, Romero A, et al. Basal cell carcinoma overlying a dermatofibroma. Actas Dermosifiliogr. 2005;96(9):612-615. 